\title{
Semptomatik Aort Darlığı Bulunan Olgularda Mekanik Kapak ve Dikişsiz Biyolojik Kapak Replasmanının Erken Dönem Sonuçlarının Karşılaştırılması
}

\author{
Comparison of Early Results of Mechanical Valve and Sutureless Biological Valve Replacement in \\ Patients with Symptomatic Aortic Stenosis
}

\section{Özcan GÜR \\ (1) 0000-0001-9321-1699 \\ Selami GÜRKAN \\ (1) 0000-0001-5391-9270}

Namık Kemal Üniversitesi Tip

Fakültesi Kalp Damar Cerrahisi AD, Tekirdağ

\section{Sorumlu Yazar \\ Corresponding Author \\ Özcan GÜR \\ ozcangur@hotmail.com}

Geliş Tarihi / Received : 01.01.2019

Kabul Tarihi / Accepted : 25.03.2019

Çevrimiçi Yayın Tarihi /

Available Online

\section{ÖZ}

Amaç: Bu çalışmada ileri semptomatik aort darlığı bulunan yüksek riskli hastalarda dikişsiz biyoprotez aort kapak ve mekanik kapak replasmanı erken dönem sonuçlarının karşılaştırılması amaçlandı.

Gerec ve Yöntemler: Ocak 2015 ve Eylül 2018 tarihleri arasında 34 (18 Erkek, 16 Kadın) dikişsiz biyoprotez aort kapak replasmanı (Edwards, Intuity) ve 50 (29 Erkek, 21 Kadın) mekanik aort kapak replasmanı (Medtronic, ATS) yapılan hasta çalışmaya alındı. Hastaların demografik verileri ve postoperatif 1 . ay verilerinin karşılaştırılması amaçlandı.

Bulgular: Mekanik kapak takılan hastalarda ejeksiyon fraksiyonu (EF) 60 (38-69), New York Kalp Cemiyeti (New York Heart Association, NYHA) siniflaması 3 (2-4), EuroSCORE 3 (0-7) ve ortalama gradiyent 56 (40-75) $\mathrm{mmHg}$ iken, dikişsiz kapak kullanılan hastalarda ise EF 52 (33-68), NYHA 4 (2-4), EuroSCORE 5 (0-7) ve ortalama gradiyent 60 (40-95) mmHg olarak saptandı. Mekanik aort kapak replasmanı yapılan hastalarda eş zamanlı olarak 9 hastaya koroner bypass, 7 hastaya mitral kapak replasmanı ve 2 hastaya triküspid ring anüloplasti yapılmıştır. Dikişsiz kapak replasmanı yapılan grupta 8 hastaya koroner bypass, 1 hastaya mitral kapak replasmanı ve 1 hastaya mitral tamir işlemi uygulanmıştır. Her iki grupta da 1 hasta postoperatif ilk 30 gün içerisinde ex olmuştur.

Sonuç: Aort darlığına bağlı operasyonlarda ileri yaş ve komorbiditelerin varlığı mortalite ve morbiditeyi arttırmaktadır. Dikişsiz aort kapağı replasmanı yüksek riskli hastalarda düsük mortalite ve morbidite, mükemmel hemodinami ve kısa implantasyon süresi ile güvenli bir biçimde kullanılabilir.

Anahtar kelimeler: Aort darlığı; dikişsiz biyolojik kapak; mekanik kapak; mortalite.

\footnotetext{
ABSTRACT

Aim: In this study, it is aimed to compare the early results of sutureless bioprosthetic aortic valve and mechanical valve replacement in high-risk patients with severe symptomatic aortic stenosis.

Material and Methods: Between January 2015 and September 2018, 34 (18 males, 16 females) patients who underwent sutureless bioprosthetic aortic valve replacement (Edwards, Intuity) and 50 (29 males, 21 females) mechanical aortic valve replacement (Medtronic, ATS) were included in the study. It is aimed to compare the demographic data and postoperative 1st month data of patients.

Results: In patients with mechanical valve insertion, ejection fraction (EF) was 60 (38-69), New York Heart Association (NYHA) classification was 3 (2-4), EuroSCORE was 3 (0-7) and mean gradient was $56(40-75) \mathrm{mmHg}$, while in patients with sutureless valve EF was determined as 52 (33-68), NYHA as 4 (2-4), EuroSCORE as $5(0-7)$ and mean gradient as $60(40-95) \mathrm{mmHg}$. In patients who underwent mechanical aortic valve replacement, 9 patients underwent coronary bypass, 7 patients underwent mitral valve replacement and 2 patients underwent tricuspid ring annuloplasty, simultaneously. In patients who underwent sutureless valve replacement, 8 patients underwent coronary bypass, 1 patient underwent mitral valve replacement and 1 patient underwent mitral repair. In both groups, a patient died within the first 30 days postoperatively.

Conclusion: Advanced age and the presence of comorbidities increase the mortality and morbidity in operations due to aortic stenosis. Sutureless aortic valve replacement can be safely used in high-risk patients with low mortality and morbidity, excellent hemodynamics and short implantation time.

Keywords: Aortic stenosis; sutureless biological valve; mechanic valve; mortality.
} 


\section{GÍRIȘ}

Semptomatik aort darlığ 1 bulunan olgularda cerrahi replasman yapılması hastalığın tedavisi için en etkili yöntemdir $(1,2)$. Hastaların yaşı, komorbiditelerin varlığı, kardiyak fonksiyonların durumu ve beraberinde başka bir işlem yapılıp yapılmaması hastanın operasyon riskini doğrudan etkilemektedir. Aort kapak replasman cerrahisi uzun süredir başarılı bir biçimde yapılsa da hastaların \%32'si yüksek riskli hastalardan oluşmakta olup işlem sonrası mortalite ve morbidite oranları yüksektir (3). Yaşlı, komorbiditesi olan hastalarda transkateter aort kapak implantasyonu (Transcatheter Aortic Valve Implantation, TAVI) umut olmuştur. PARTNER 1 ve 2 çalışmalarında ileri aort darlığı bulunan orta ve yüksek riskli hasta gruplarında TAVI işlemi, medikal tedaviye üstün bulunsa da cerrahi ile benzer sonuçlar elde edildiği bildirilmiştir $(4,5)$. TAVI işlemi sonrası $\% 2$ aort rüptürü, $\% 2$ koroner osteal tıkanma, \%6 paravalvüler kaçak, \%5,5 nörolojik olay, leaflet trombozu ve kalıcı pil ihtiyacı geliştiği bildirilmiştir (6). Gelişen bu komplikasyonlar konvansiyonel AVR ile karşılaştırıldığında yüksek olduğu görülmektedir $(7,8)$. Bu hasta gruplarında son dekadda dikişsiz aort kapak kullanımı ile başarılı sonuçlar elde edilmektedir. Dikişsiz olarak implante edilen bu biyolojik kapakların, kısa aortik kros klemp süresi, kısa ameliyat süresi, düşük komplikasyon oranları ve minimal invaziv kalp cerrahisine uygun olması gibi önemli avantajları bulunmaktadır (9). Bu çalışmada mekanik bileaflet kapak ve biyolojik dikişsiz aort kapak replasmanı yapılan olguların erken dönem sonuçlarının karşılaştırılması amaçlanmıştır.

\section{GEREÇ VE YÖNTEMLER}

Ocak 2015 ve Eylül 2018 tarihleri arasında semptomatik ileri aort darlığı bulunan 34 dikişsiz biyoprotez aort kapak replasman1 (Edwards Intuity, Edwards Lifesciences, Irvine, CA, USA) ve 50 mekanik bileaflet aort kapak replasmanı (ATS valve) (Medtronic, Minneapolis, MN, USA) yapılan hasta çalışmaya alındı. Çalışmaya başlamadan önce Namık Kemal Üniversitesi Tıp Fakültesi etik kurulundan onay alındı (2018/30/03/03). Çalışma retrospektif olarak veriler toplanarak tamamlandı. Çalışma sirasında hastaların New York Kalp Cemiyeti (New York Heart Association, NYHA) fonskiyonel kapasitesi, EuroSCORE (Europen System for Cardiac Operative Risk Evaluation) ve ekokardiyorafik parametreleri karşılaştırıldı. İnfektif endokardit sebebiyle aort kapak cerrahisi yapilan veya beraberinde asendan aort replasmanı yapılan olgular, ekokardiyografide biküspid aort saptanan olgular çalışma dışı bırakıldı.

\section{Cerrahi Teknik}

Cerrahi teknik sternotomi sonrası arteriyel ve venöz kanülasyon yapılarak kardiyopulmoner bypassa girildi. Kros klemp ve kardiyoplejik arrest sonrası standart aortotomi yapıldı. Aort darlığına sebep olan kalsifikasyonlar ve leafletler 2 mm'lik anulus dokusu bırakılacak şekilde temizlendi. Kapak ölçeri yardımı ile kullanılacak kapak ölçüsü belirlenerek uygun ölçüde dikişsiz biyoprotez kapak açılarak üç dakika süreyle izotonik serumla yıkandı. Beraberinde koroner bypass yapılacak olguların distal anastomozları, mitral kapak replasmanı veya tamiri yapılacak olguların cerrahileri yapıldı. Ardından paraşüt tekniği kullanılarak dikişsiz biyolojik kapak anulusa yerleștirildi. Bu teknik sırasında leafletlerin en derin kısmından 3 adet plegitli sütür geçirilerek dikişsiz biyolojik kapak sneare yardımı ile anulusa oturtuldu. Kapak ölçüsüne uygun basınçta balon indeflatör yardımı ile şişirilerek kapak yerine yerleştirildi (Kapak ölçüsüne göre 3 ile 5 atmosfer basınç aralığında). Balon indirilerek taşıyıcı sistem geri çekildi ve paraşüt tekniği için konulan dikişler yerinden alınarak koroner ostiumlar kontrol edildi. Ardından aortotominin kapatılmasına geçildi (Resim 1).

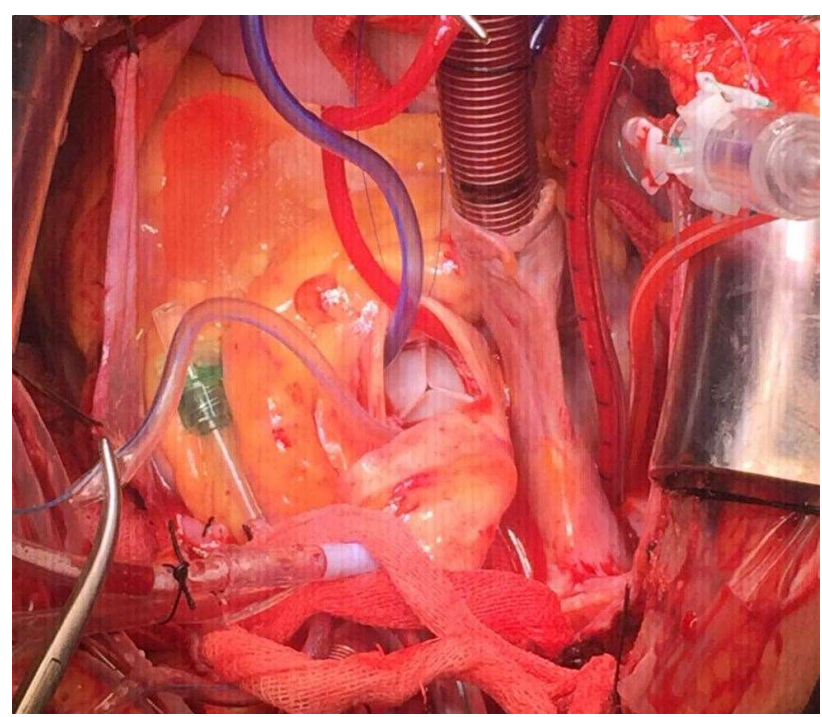

Resim 1. Dikişsiz biyolojik kapak replasmanı yapılan olgunun işlem sırasındaki görünümü

Mekanik aort kapak replasmanı yapılacak olgularda ise plejitsiz kapak sütürleri ile kapak yerine oturtularak dikişler bağlandı. Koroner ostiumlar kontrol edildikten sonra aortotominin kapatılmasına geçildi.

Aortotomi kapatılarak kros klemp kaldırılmadan önce koroner bypass yapılan hastaların proksimal anastomozları yapıldı. Hava çıkarma işleminin ardından kros klemp kaldırılarak kardiyopulmoner bypasstan çıkıldı. Kanama kontrolünü takiben geçici pace maker teli ve dren yerleştirilerek sternum çelik tellerle yaklaştırıldı.

\section{İstatistiksel Analiz}

Çalışmanın istatistiksel analizinde SPSS for Mac v.20 istatistik paket programı kullanıldı. Sayısal verilerin normal dağılıma uygunluğu Kolmogorov-Smirnov testi ile incelendi. Normal dağılım gösterenler ortalama \pm standart sapma, normal dağılım göstermeyenler ise ortanca (minimum-maksimum) olarak sunuldu ve Student $t$ testi veya Mann-Whitney-U testi ile karşılaştırıldı. Kategorik değişkenler sayı ve yüzde olarak belirtildi. Kategorik değişkenlerin analizi Pearson ki-kare ve Fisher's exact testleri ile yapıldı. İstatistiksel analizlerde $\mathrm{p}<0,05$ olmas1 durumunda anlamlı olarak değerlendirildi.

\section{BULGULAR}

Çalışmaya toplam 84 hasta alındı. Hastaların ortalama yaşı $65,3 \pm 11,8$ olarak saptand. Hastaların $47(\% 56,0)$ 'si erkek ve $37(\% 44,0)$ 'si kadın idi. Otuz dört hastaya biyolojik dikişsiz kapak replasmanı yapılırken, 50 hastaya mekanik 
bileaflet aort kapak replasmanı yapıldı. Mekanik kapak replasmanı yapılan hastalarda eş zamanlı olarak 9 hastaya koroner bypass, 7 hastaya mitral kapak replasmanı ve 2 hastaya trikuspid ring anuloplasti yapılmıştır. Dikişsiz kapak replasmanı yapılan grupta 8 hastaya koroner bypass, 1 hastaya mitral kapak replasmanı ve 1 hastaya mitral tamir işlemi uygulanmıştır.

Mekanik kapak hastalarında ortalama yaş 58,3 $\pm 10,1$ iken biyoprotez replasmanı yapılan olgularda ise 75,6 $\pm 4,2$ olarak saptandı. Mekanik kapak replasmanı yapılan hastaların 29'u erkek ve 21'i kadın, biyoprotez replasmanı yapılan olguların ise 18 'i erkek ve 16's1 kadınd. Hastaların demografik verileri ve preoperatif ekokardiyografik verilerinin karşılaştırılması Tablo 1'de gösterilmiştir.

Her iki grup arasında hipertansiyon, diyabetes mellitus, kronik böbrek yetmezliği, kronik obstruktif akciğer hastalığı açısından anlamlı fark saptanmadı. Preoperatif ekokardiyografik verilere bakıldığında biyolojik dikişsiz aort kapak replasmanı yapılan grup ile mekanik kapak replasmanı yapılan grup arasında yaş $(\mathrm{p}<0,001)$, ejeksiyon fraksiyonu $(p=0,012)$, NYHA $(p<0,001)$ ve ortalama gradiyent $(\mathrm{p}=0,017)$ açısından istatistiksel olarak anlamlı farklılık olduğu tespit edildi (Tablo 1).

Olguların peroperatif verilerine bakıldığında, operasyon sürelerinin dikişsiz kapak grubunda anlamlı olarak düşük olduğu saptandı $(\mathrm{p}<0,001)$. Kros klemp süresi dikişsiz kapak grubunda 49 (25-117) dakika olarak saptanırken mekanik aort kapak replasmanı yapılan grupta 99 (33-171) dakika olarak saptandi. Toplam bypass süreleri karşılaştırıldığında dikişsiz kapak replasmanı yapılan grupta 64 (42-198) dakika saptanırken, mekanik kapak grubunda ise 122 (26-202) dakika saptand1. Toplam bypass süreleri arasındaki farkın da istatistiksel olarak anlamlı olduğu görüldü $(\mathrm{p}<0,001)$. Olguların postoperatif dönemde yoğun bakım yatış, revizyon ve taburculuk süreleri açısından herhangi bir fark saptanmadı. Olguların peroperatif ve postoperatif verileri Tablo 2'de ayrintılı olarak gösterilmiştir. Olguların postoperatif 1 . ay kontrollerinde mortalite $(p=1,000)$, septum kalınlığ $(\mathrm{p}=0,276)$, endsistolik volüm $(\mathrm{p}=0,077)$, enddiastolik volüm $(p=0,113)$ ve ortalama gradiyent $(p=0,114)$ açısından anlamlı fark saptanmadi. Ejeksiyon fraksiyonu preoperatif dönemdeki ekokardiyografi gibi dikişsiz kapak grubunda mekanik kapak grubuna göre anlamlı olarak düşük saptandı $(\mathrm{p}<0,001)$. Tablo 3 'te postoperatif 1 . ay takipleri ayrıntılı olarak gösterilmiştir.

\section{TARTIŞMA}

Tüm dünyada semptomatik ileri aort darlığı sebebiyle yılda 200.000 civarında aort kapak replasmanı yapılmaktadır (10). Aort kapak replasmanı yapılması ileri aort darlığı bulunan olgularda altın standart tedavi yöntemidir (11). Operasyon için yüksek riskli hastalarda TAVI, aort kapak replasmanına alternatif bir yöntem olarak öne çıksa da dekalsifikasyon yapılmaması ve stentin anülüse uyguladığı yüksek basınç paravalvüler kaçak, kapak migrasyonu, leaflet trombozu, aort rüptürü, kalsifik materyal embolisine bağlı nörolojik olay ve kalıcı pil gereksinimi gibi ciddi komplikasyonlara sebep olmaktadır (12). Yüksek riskli bu hasta gruplarında mortalite ve morbidite oranlarının azaltılması ayrıca mekanik kapak ile elde edilen uzun dönem başarılı
Tablo 1. Hastaların demografik ve preoperatif ekokardiyografik verileri

\begin{tabular}{lccc}
\hline & $\begin{array}{c}\text { Mekanik } \\
\text { Kapak } \\
(\mathbf{n = 5 0 )}\end{array}$ & $\begin{array}{c}\text { Dikişsiz } \\
\text { Kapak } \\
(\mathbf{n = 3 4 )}\end{array}$ & $\mathbf{p}$ \\
\hline $\begin{array}{l}\text { Cinsiyet } \\
\quad \text { Erkek }\end{array}$ & $29(\% 58,0)$ & $18(\% 52,9)$ & 0,647 \\
Kadın & $21(\% 42,0)$ & $16(\% 47,1)$ & \\
Yaş & $58,3 \pm 10,1$ & $75,6 \pm 4,2$ & $<\mathbf{0 , 0 0 1}$ \\
HT & $30(\% 60,0)$ & $20(\% 58,8)$ & 0,914 \\
KBY & $1(\% 2,0)$ & $1(\% 2,9)$ & 1,000 \\
DM & $30(\% 60,0)$ & $20(\% 58,8)$ & 0,914 \\
KOAH & $16(\% 32,0)$ & $14(\% 41,2)$ & 0,389 \\
Üre (mg/dL) & $34(20-83)$ & $38(19-84)$ & 0,278 \\
Kreatinin (mg/dL) & $0,8(0,4-1,9)$ & $0,8(0,7-1,6)$ & 0,613 \\
EF & $60(38-69)$ & $52(33-68)$ & $\mathbf{0 , 0 1 2}$ \\
Ort. Grd (mmHg) & $56(40-75)$ & $60(40-95)$ & $\mathbf{0 , 0 1 7}$ \\
Maks. Grd (mmHg) & $85(60-100)$ & $89(62-114)$ & 0,173 \\
NYHA Sınıflamas1 & $3(2-4)$ & $4(2-4)$ & $<\mathbf{0 , 0 0 1}$ \\
EuroSCORE & $3(0-7)$ & $5(0-7)$ & $\mathbf{0 , 0 0 2}$ \\
\hline
\end{tabular}

HT: Hipertansiyon, KBY: Kronik Böbrek Yetmezliği, DM: Diyabetes Mellitus, KOAH: Kronik Obstruktif Akciğer Hastalığı, EF: Ejeksiyon Fraksiyonu, Ort. Grd: Ortalama Gradiyent, Maks. Grd: Maksimum gradiyent, NYHA: New York Heart Association, EuroSCORE: Europen System for Cardiac Operative Risk Evaluation, tanımlayıcı
istatistikler, kategorik değişkenler için sayı ve yüzde, sayısal değişkenler için istatistikler, kategorik değişkenler için sayı ve yüzde, sayısal değişkenler
ortalama \pm standart sapma veya ortanca (minimum-maksimum) şeklinde verilmiştir.

Tablo 2. Peroperatif veriler ve postoperatif yoğun bakım ve servis takipleri

\begin{tabular}{lccc}
\hline & $\begin{array}{c}\text { Mekanik } \\
\text { Kapak } \\
(\mathbf{n = 5 0 )}\end{array}$ & $\begin{array}{c}\text { Dikişsiz } \\
\text { Kapak } \\
(\mathbf{n = 3 4 )}\end{array}$ & $\mathbf{p}$ \\
\hline Kapak Ölçüsü & $21(18-27)$ & $21(19-23)$ & 0,137 \\
KKZ (dk) & $99(33-171)$ & $49(25-117)$ & $<\mathbf{0 , 0 0 1}$ \\
TBZ (dk) & $122(26-202)$ & $64(42-198)$ & $<\mathbf{0 , 0 0 1}$ \\
YBU süresi (gün) & $3(2-8)$ & $3(2-8)$ & 0,640 \\
Drenaj (mL) & $350(150-1200)$ & $375(250-1100)$ & 0,602 \\
Revizyon & $6(\% 12,0)$ & $3(\% 8,8)$ & 0,733 \\
Reentübasyon & $5(\% 10,0)$ & $1(\% 2,9)$ & 0,394 \\
Yatış süresi (gün) & $7(6-16)$ & $7(4-24)$ & 0,109 \\
\hline
\end{tabular}

KKZ: Kros Klemp Zamanı, TBZ: Toplam Bypass Zamanı, YBU: Yoğun Bakım Ünitesi Yatış, tanımlayıcı istatistikler sayısal değişkenler için ortanca (minimum-maksimum) kategorik değişkenler için sayı ve yüzde şeklinde verilmiştir.

Tablo 3. Hastaların postoperatif 1. ay takiplerinde mortalite ve ekokardiografik veriler

\begin{tabular}{lccc}
\hline & $\begin{array}{c}\text { Mekanik } \\
\text { Kapak } \\
(\mathbf{n = 5 0})\end{array}$ & $\begin{array}{c}\text { Dikisssiz } \\
\text { Kapak } \\
(\mathbf{n}=\mathbf{3 4})\end{array}$ & $\mathbf{p}$ \\
\hline EF & $60(45-68)$ & $50(30-65)$ & $<\mathbf{0 , 0 0 1}$ \\
Ort. Grd (mmHg) & $15(5-25)$ & $12(8-26)$ & 0,114 \\
Maks. Grd (mmHg) & $25(18-40)$ & $22(15-32)$ & $\mathbf{0 , 0 0 4}$ \\
LVESD (mm) & $32(22-44)$ & $32(28-44)$ & 0,077 \\
LVEDD (mm) & $52(42-70)$ & $52(48-72)$ & 0,113 \\
Septum Kalınlığ $(\mathrm{mm})$ & $12(9-15)$ & $12(9-18)$ & 0,276 \\
Mortalite & $1(\% 2,0)$ & $1(\% 2,9)$ & 1,000 \\
\hline
\end{tabular}

EF: Ejeksiyon Fraksiyonu, Ort. Grd: Ortalama Gradiyent, Maks Grd: Maksimum gradiyent, LVESD: Left Ventricular End Systolic Diameter, Sol Ventrikül Sistol Sonu Çapı, LVEDD: Left Ventricular End Diastolic Diameter, Sol Ventrikül Diyastol Sonu Çapı, tanımlayıcı istatistikler sayısal değişkenler için ortanca (minimum-maksimum) kategorik değişkenler için sayı ve yüzde şeklinde verilmiştir. 
sonuçlarının elde edilmesi amacıyla biyolojik dikişsiz kapakların kullanımı gündeme gelmiştir. Bu kapaklarda mekanik kapak implantasyonundan farklı olarak kapağın anülüse tutunmasında kapak dikişleri kullanılmamaktadır. İleri derecede kalsifik anülüslerde kapak dikişlerinin kalsifik anülüsten geçmesi sorun olmakla beraber işlem sonrasında anülüsün yırtılması ile paravalvüler kaçak oluşumuna sebep olmaktadır (13). Kalsifik anülüs temizlendikten sonra dikişsiz biyolojik kapağın yerleştirilmesi bu riski ortadan kaldırmakta ve kapağın altındaki etek yardımı ile mikroembolizasyon riski azaltmaktadır. Dikişsiz kapak kullanımı operasyon süresini kısaltmaktadır. Operasyon süresinin uzaması kardiyopulmoner bypass sırasında kanın yapay yüzey ile daha uzun süre temasına sebep olmakta ve inflamatuar reaksiyon sıklığı artmaktadır. Mikroembolilere bağlı organ disfonksiyonlarına, mortalite ve morbiditenin artmasına sebep olmaktadır (14). Bu çalışmada yüksek riskli hasta grubunda dikişsiz kapak kullanıldı ve işlem süresinin konvansiyonel yönteme göre anlamlı derecede düşük olduğunu saptand. Her iki grupta da işlem sonrası dönemde kapak disfonksiyonu, nörolojik olay, kapak trombozu gibi komplikasyonlar ile karşılaşılmadı. İşlem sonrası dönemde dikişsiz kapak grubu istatiksel olarak daha yüksek riskli olmasına karşılık (NYHA, EF, EuroSCORE) revizyon oranları, yoğun bakım kalış, reentübasyon, taburculuk süresi ve mortalite oranları açısından anlamlı fark saptanmadı. Her iki grupta da 1'er hasta postoperatif dönemde düşük kardiyak output gelişmesine takip kaybedildi.

Operasyon sonrası dönemde AV blok gelişmesi ve kalıcı pil takılması hasta konforunu azaltırken morbidite oranlarını arttırmaktadır. Dikişsiz kapak takılan olgularda yetersiz dekalsifikasyon, büyük boy kapak tercih edilmesi, işlem öncesi dönemde sol dal bloğunun olması operasyon sonrası dönemde AV blok ve kalıcı pil ihtiyac1 sıklığını arttırmaktadır $(15,16)$. TAVI yapılan olgularda ise AV blok gelişme sıklığı ve kalıcı pil ihtiyacı \%26'ya kadar çıkmaktadır (17). Bu çalışmada her iki grupta da kalıcı AV blok ve kalıcı pil ihtiyacına gereksinim olmamıştır.

Mekanik kapak kullanımı sonrasında hastalar ömür boyu warfarin tedavisi almaktadır. Warfarine bağlı komplikasyon özellikle yaşlı ve komorbiditesi bulunan olgularda yüksektir (2). Biyolojik dikişsiz kapaklarda ise ilk 3 ay warfarin kullanımı sonrasında hastaların warfarin kullanmasına ihtiyaç bulunmaması büyük avantaj olarak göze çarpmaktadır.

Yüksek riskli hastalarda mekanik kapak kullanımı sonucu konvansiyonel yöntemlerde mortalite \%4-10 arasında değişmektedir (18). Biyolojik dikişsiz kapak takılan olgularda ise mortalite daha düşük seyretmektedir. Kocher ve ark. (19) tarafindan yapılan çalışmada biyolojik dikişsiz kapak kullanımı sonrası 30 günlük mortalite $\% 2,1$ saptanırken, Shrestha ve ark. (9) tarafindan yapılan çalışmada da 30 günlük mortalite $\% 3,4$ bulunmuştur. $\mathrm{Bu}$ çalışmada da 30 günlük mortalite $\% 2,9$ olarak saptandı. Mortalite açısından düşük riskli mekanik kapak kullanılan hastalar ile istatistiksel olarak anlamlı bir farklılık saptanmadı. Dikişsiz biyolojik kapak uygulamasının olumsuz özellikleri olarak biyolojik tüm kapaklarda olduğu gibi kapağın yapısal erken dejenerasyonu sayılabilir. Bu durumda tekrar cerrahi uygulanabileceği gibi TAVI uygulanarak "valve in valve" yapılabilir. "Valve in valve" uygulanması mekanik kapak kullanılan olgulara göre avantaj sağlamaktadır.

Sonuç olarak, ileri aort darlığı bulunan yüksek riskli hasta gruplarında biyolojik dikişsiz aort kapak kullanımının düşük mortalite ve morbidite, mükemmel hemodinamik performans ile özellikle yaşlı hastalarda ilk tercih olabileceği düşünülmektedir. Genç hastalarda kullanımı ile ilgili uzun takip süresi ve yüksek hasta sayılı çalışmalara ihtiyaç bulunmaktadır.

\section{KAYNAKLAR}

1. Eichstaedt HC, Easo J, Härle T, Dapunt OE. Early singlecenter experience in sutureless aortic valve implantation in 120 patients. J Thorac Cardiovasc Surg. 2014;147(1):370-5.

2. Altintas G, Diken AI, Hanedan O, Yurdakok O, Ozyalcin S, Kucuker SA, et al. The Sorin Freedom SOLO stentless tissue valve: early outcomes after aortic valve replacement. Tex Heart Inst J. 2013;40(1):50-5.

3. Iung B, Baron G, Butchart EG, Delahaye F, GohlkeBärwolf C, Levang OW, et al. A prospective survey of patients with valvular heart disease in Europe: The Euro Heart Survey on Valvular Heart Disease. Eur Heart J. 2003;24(13):1231-43.

4. Leon MB, Smith CR, Mack M, Miller DC, Moses JW, Svensson LG, et al. Transcatheter aortic-valve implantation for aortic stenosis in patients who cannot undergo surgery. N Engl J Med. 2010;363(17):1597607.

5. Leon MB, Smith CR, Mack MJ, Makkar RR, Svensson LG, Kodali SK, et al. Transcatheter or surgical aorticvalve replacement in intermediate-risk patients. N Engl J Med. 2016;374(17):1609-20.

6. Webb JG, Pasupati S, Humphries K, Thompson C, Altwegg L, Moss R, et al. Percutaneous transarterial aortic valve replacement in selected high-risk patients with aortic stenosis. Circulation. 2007;116(7):755-63.

7. Kodali SK, Williams MR, Smith CR, Svensson LG, Webb JG, Makkar RR, et al. Two-year outcomes after transcatheter or surgical aortic-valve replacement. N Engl J Med. 2012;366(18):1686-95.

8. Smith CR, Leon MB, Mack MJ, Miller DC, Moses JW, Svensson LG, et al. Transcatheter versus surgical aortic-valve replacement in high-risk patients. N Engl J Med. 2011;364(23):2187-98.

9. Shrestha M, Folliguet T, Meuris B, Dibie A, Bara C, Herregods MC, et al. Sutureless Perceval S aortic valve replacement: a multicenter, prospective pilot trial. J Heart Valve Dis. 2009;18(6):698-702.

10. Brown JM, O’Brien SM, Wu C, Sikora JA, Griffith BP, Gammie JS. Isolated aortic valve replacement in North America comprising 108,687 patients in 10 years: changes in risks, valve types, and outcomes in the Society of Thoracic Surgeons National Database. J Thorac Cardiovasc Surg. 2009;137(1):82-90.

11. Walther T, Blumenstein J, van Linden A, Kempfert J. Contemporary management of aortic stenosis: surgical aortic valve replacement remains the gold standard. Heart. 2012;98(Suppl 4):iv23-9.

12. Yan TD, Cao C, Martens-Nielsen J, Padang R, Ng M, Vallely MP, et al. Transcatheter aortic valve 
implantation for high-risk patients with severe aortic stenosis: A systematic review. J Thorac Cardiovasc Surg. 2010;139(6):1519-28.

13. Folliguet TA, Laborde F, Zannis K, Ghorayeb G, Haverich A, Shrestha M. Sutureless perceval aortic valve replacement: results of two European centers. Ann Thorac Surg. 2012;93(5):1483-8.

14. Ranucci M, Frigiola A, Menicanti L, Castelvecchio S, de Vincentiis C, Pistuddi V. Aortic cross-clamp time, new prostheses, and outcome in aortic valve replacement. J Heart Valve Dis. 2012;21(6):732-9.

15. Dawkins S, Hobson AR, Kalra PR, Tang AT, Monro JL, Dawkins KD. Permanent pacemaker implantation after isolated aortic valve replacement: incidence, indications, and predictors. Ann Thorac Surg. 2008;85(1):108-12.

16. Mazine A, Teoh K, Bouhout I, Bhatnagar G, Pelletier M, Voisine P, et al. Sutureless aortic valve replacement: a Canadian multicentre study. Can J Cardiol. 2015;31(1):63-8.

17. Goldenberg G, Kusniec J, Kadmon E, Golovchiner G, Zabarsky R, Nevzorov R, et al. Pacemaker mplantation after transcatheter aortic valve implantation. Am J Cardiol. 2013;112(10):1632-4.

18. Di Eusanio M, Fortuna D, De Palma R, Dell'Amore A, Lamarra M, Contini GA, et al. Aortic valve replacement: results and predictors of mortality from a contemporary series of 2256 patients. J Thorac Cardiovasc Surg. 2011;141(4):940-7.

19. Kocher AA, Laufer G, Haverich A, Shrestha M, Walther T, Misfeld M, et al. One-year outcomes of the Surgical Treatment of Aortic Stenosis With a Next Generation Surgical Aortic Valve (TRITON) trial: a prospective multicenter study of rapid-deployment aortic valve replacement with the EDWARDS INTUITY Valve System. J Thorac Cardiovasc Surg. 2013;145(1):110-5. 